\title{
Discussion on the Form and Characteristics of Orienteering in Colleges and Universities
}

\author{
Zhang Shubing and Zeng Jianying
}

(NanChang Institute of Science and Technology, Nanchang, 330108)

\section{Keywords: Orienteering; Colleges and Universities; Characteristics}

\begin{abstract}
Orienteering has been developed for a short time in our country. It can be used as a sport as well as a recreational sport. In order to improve people's comprehensive physique level, our country will promote this outstanding sport to the general public. Colleges and universities are the place where orienteering is developed fastest and popularized most widely. Most athletes in colleges and universities have excellent physique, technical level and physical qualities. Therefore, college athletes are the main targets for the special training of orienteering. At present, the main representative of orienteering level in our country is the orienteering level of colleges and universities. However, for the physical quality, there is a big gap between the athletes in our colleges and universities and foreign countries, which is also the focus of training and direction. This paper studies the form and characteristics of orienteering in colleges and universities.
\end{abstract}

\section{Introduction}

Orienteering is a sport that participants use both topographic maps and compass to find a number of checkpoints plotted on the map in the prescribed order and finish the race in the shortest time. It integrates physique and intelligence. It is not only a competitive sport but also a leisure event, and it can be regarded as an emerging sport event in our country. After extensive promotion of various social forces, orienteering has been rapidly developed in our country in recent years. This sport in colleges and universities is developed the fastest and has the highest level of skills. Especially in colleges and universities, college athletes have the higher requirements for physical fitness, intelligence and psychology in directional sports, and the unique natural structure conditions in colleges and universities also provide good site conditions for the development of orienteering. So orienteering has been developed particularly rapidly in colleges and universities. However, as a whole, the competitive level of China's orienteering still lags far behind other countries. China is in an exploratory stage in training methods and means of orienteering. This paper studies the forms and characteristics of orienteering in colleges and universities. Hope it can be helpful to enhance training, and promote orienteering into the next step.

\section{Introduction of Orienteering}

As a new form of field activity, orienteering originates from Europe. The athletes can use maps and compass to visit various plots indicated on the map. The one who uses the shortest time to reach all the targets is the winner. It is attracting more and more people in all parts of the world to be passionate about it. It is both an outdoor recreation and a recreational sport, but also a competitive sport. The physical and mental requirements of the players should be higher. In addition to compass and map, it does not require special equipment to participate in orienteering, so it is a more economical sport.

Orienteering is usually held in the forest, but also in parks, campuses and even in the street of urban areas. It is easy to design a route that meets the needs of the participants of different ages, gender, physique and orientational skills. Therefore, it will not be subject to conditions to participate in orienteering.

The youngest orienteering contestants are only 3 years old, and the oldest has reached more than 80 years old. As more and more people take part in outdoor sports that return to nature as a theme, orienteering has become an essential survival skill. 
Orienteering competition is one of the competition events that were officially permitted by the International Orienteering Federation (IOF), which as referred to as the IOF.

Orienteering is also a type of personal experiential exercise. This may also be arguably one of its drawbacks. The current orienteering is mainly carried out in forests and parks. Since there are many restrictions on live viewing or on television, it is hard for viewers to experience the challenges, stimuli and pleasures.

\section{Curriculum Resources Characteristics of Orienteering in Colleges and Universities}

The ability to use OCAD mapping software and draw maps on site are the two abilities that orienteering teachers must have. The natural environment we face is constantly changing, so the maps we use cannot be static. In the actual teaching of orienteering, we often need to modify the map or the route according to the actual situation of our teaching in order to achieve the teaching goal. From the survey response situation, these several colleges and universities that carry out orienteering training better, the professional level of their teachers is still relatively good. The teachers canmake on-site mapping skillfully reach $66.7 \%$, while their ability in using OCAD software isnot very good. The conditions of owning orienteering professional equipment of the surveyed objects is more optimistic,the number of units possessing electronic equipment and mechanical equipment reach $77.8 \%$. Teaching material is an important basis to guide students to learn, training. The physical education content embodied in teaching material is an important condition to achieve the goal of physical education. Statistics show that most of the colleges and universities participating in the survey use a variety of teaching materials for training and teaching, indicating that the current versions of teaching materials cannot fully meet the needs of the teaching and training of orienteering teaching in colleges and universities. The contents of current teaching materials are basically the same, mainly including the origin and development, the basic skills, the competition rules of orienteering, etc. There are few references about teaching methods and means, teaching organization and implementation, and teaching process control about orienteering, or they are not comprehensive. So it is difficult to choose a teaching material that is very suitable for the norms of orienteering in colleges and universities. The theoretical system of orienteering teaching is to be perfected.

\section{Special Physical Training of Orienteering in Colleges and Universities}

The significance of carrying out orienteering special physical training. Orienteering need athletes have sufficient endurance and physical strength, thus the main purpose of special physical training is to improve the athletes' energy reserve level. For the traditional sports such as long-distance running, athletics and so on, as the venue, distance are relatively fixed, the training method is relatively fixed. Before the game, a sound training program can be developed based on the physical condition of athletes to achieve the target speed in the game. However, orienteering is generally carried out in the complicated and changeable terrain in the wild. The changes in the distance and road conditions are very great. Physical trainingcan refer to the method of long-distance running training, but should follow the rhythm of orienteering, that is, different forms of running are the training contents. Special physical training cannot be carried out in the outdoor environmentevery time, so it can also get better training results to take appropriate training methodsin the campusaccording to the training objectives.

Independent orienteering special physical training. In orienteering, the athletes cannot knowthe others' conditions, reflecting the independence characteristics of the sport, and they are not accompanied by a coach, all training needs to be done by the athletes. In the daily physical training, but athletes also needs to be trained continuously to adapt to the independence feature. At the beginning of physical training, the coach can supervise on the one hand and point out the athletes' action defects and mistakes. After a period of training, the athletes' consciousness and ability to independently complete the training task should be gradually cultivated. The coach should deliberately give the athletes the space and time for independent training so that the athletes can 
develop their self-restraint and self-monitoring ability so that they can accomplish the goal of movement efficiently and independently during the actual exercise.

Strategy of special physique training in orienteering. China's standards for the development of orienteering are: the women elite group distance is $10 \mathrm{~km}$ to $25 \mathrm{~km}$; menelite group distance is 12 $\mathrm{km}$ to $20 \mathrm{~km}$. In the traditional sports, the marathon has a smooth running route and the long-distance running has a flexible plastic runway. However, the orienteering needs to be carried out in a complex field environment, and the athlete is required to adapt to different terrains with good training. So, appropriate training methods need to be adopted according to different situations.

\section{Conclusion}

The timing and location of orienteering courses in colleges and universities directly affect the selection and structural design of teaching contents. Extracurricular hours and extracurricular venues should be included in the orienteering sports curriculum. Orienteering has its own event characteristics. The professional ability of teachers, a variety of map resources, adequate orientation equipment, reasonable teaching materials and rich teaching resources are the important guarantee for the curriculum development. In orienteering sport training in colleges and universities, the technical level and physical fitness of college and universities students can be effectively improvedwith appropriate training methods combining with the characteristics of orienteering.

\section{References}

[1] Xue L. On the Orienteering Courses to Improve Physical Fitness of College Students: A Case Study of Jinzhong University[J]. Wushu Science, 2015.

[2] Xie X. Research on the Current Situation of College Orienteering of Anhui_—-In case of Anhui Normal University[J]. Journal of Guangxi Normal University for Nationalities, 2012.

[3] Li X. The harmonious generation between Orienteering and Physical Education in Colleges and Universities[C]// 2015 International Conference on Industrial Technology and Management Science. Atlantis Press, 2015.

[4] Tan G. Orienteering and Physical Education in Colleges and Universities Produce Harmony[J]. Journal of Huaihua University, 2006.

[5] Long X D, Wang Y F, Fan H L. Empirical Study of Multimedia Technology in the Orienteering Teaching of Males in Colleges \& Universities[J]. Advanced Materials Research, 2012, 428:176-180.

[6] Ren W H. Study on the Construction of University Orienteering Curriculum System[J]. Journal of Henan Institute of Education, 2014.

[7] Zhou H, Jiang T, Ji L. Study on the effect of orienteering to improve the physical quality of college students in colleges[J]. Journal of Chemical \& Pharmaceutical Research, 2014.

[8] Chang Y, Li W. Orienteering to promote science research college talent cultivation[J]. Contemporary Sports Technology, 2014.

[9] Fei-Teng W U, Chen H, Wang H. Exploring on Dual-Score Teaching Mode to Be Applied in College Orienteering[J]. Sports Science Research, 2011.

[10] Wang Y, Wang L. Optimal Design of Teaching Research on Orienteering Curriculum in Universities[J]. Journal of Jilin Institute of Physical Education, 2011.

[11] Qin Y E. Analysis of Present Situation of the Ecological Environment of College Orienteering Sports Education in Jiangxi Province[J]. Sports Science Research, 2014.

[12] Wang H L. A Survey \& Analysis on Current Teaching Situation of Orienteeringin Shihezi University[J]. Science \& Technology Information, 2011. 